\title{
Intravenous infusion route in maternal resuscitation: a scoping review
}

\author{
Eishin Nakamura 1,2*, Shinji Takahashi ${ }^{2,3}$, Shigetaka Matsunaga ${ }^{2,4}$, Hiroaki Tanaka ${ }^{2,5}$, Marie Furuta ${ }^{2,6}$, \\ Atsushi Sakurai ${ }^{2,7}$ and the Japan Resuscitation Council (JRC), Guideline Editorial Committee
}

\begin{abstract}
Background: The concept that upper extremities can be used as an infusion route during cardiopulmonary resuscitation in pregnant women is a reasonable recommendation considering the characteristic circulation of pregnant women; however, this method is not based on scientific evidence.

Objective of the review: We conducted a scoping review to determine whether the infusion route should be established above the diaphragm during cardiopulmonary resuscitation in a pregnant woman.

Discussion: We included randomized controlled trials (RCTs) and non-RCTs on the infusion of fluids in pregnant women after 20 weeks of gestation requiring establishment of an infusion route due to cardiac arrest, massive bleeding, intra-abdominal bleeding, cesarean section, severe infection, or thrombosis. In total, 3150 articles from electronic database were extracted, respectively. After title and abstract review, 265 articles were extracted, and 116 articles were extracted by full-text screening, which were included in the final analysis. The 116 articles included 78 studies on infusion for pregnant women. The location of the intravenous infusion route could be confirmed in only 17 studies, all of which used the upper extremity to secure the venous route.

Conclusion: Pregnant women undergo significant physiological changes that differ from those of normal adults, because of pressure and drainage of the inferior vena cava and pelvic veins by the enlarged uterus. Therefore, despite a lack of evidence, it seems logical to secure the infusion route above the diaphragm when resuscitating a pregnant woman.
\end{abstract}

Keywords: Cardiopulmonary resuscitation, Pregnancy, Resuscitation, Intravenous infusion, Scoping review

\section{Background}

The Japan Resuscitation Council (JRC) has published resuscitation guidelines in 2010, 2015, and 2020. ITherefore, a new algorithm for resuscitation of pregnant women was developed. Although the number of maternal deaths in Japan is approximately 4 per 100,000 deliveries [1], the effect of circuatory dynamics of pregnant

\footnotetext{
* Correspondence: einaka@saitama-med.ac.jp

${ }^{1}$ Center for Maternal, Fetal and Neonatal Medicine, Saitama Medical Center, Saitama Medical University, 1981 Kamoda, Kawagoe-shi, Saitama 350-8550, Japan

2Japan Resuscitation Council, Maternal group, Tokyo Japan, 2-5-4 Yoyogi, Sibuya-ku, Tokyo 151-0053, Japan

Full list of author information is available at the end of the article
}

women generates a need to determine effective and evidence-based maternal resuscitation methods.

The American Heart Association (AHA) developed and illustrated an algorithm based on the International Consensus Conference on Cardiopulmonary Resuscitation and Emergency Cardiovascular Care Science With Treatment Recommendations (CoSTR) [2], which stated that intravenous access should be considered above the diaphragm [3]. This statement is justifiable considering the special circulatory dynamics of pregnancy, but we believe that it needs to be supported by evidence and not by a scientific recommendation based on evidence.

(c) The Author(s). 2021 Open Access This article is licensed under a Creative Commons Attribution 4.0 International License, which permits use, sharing, adaptation, distribution and reproduction in any medium or format, as long as you give appropriate credit to the original author(s) and the source, provide a link to the Creative Commons licence, and indicate if changes were made. The images or other third party material in this article are included in the article's Creative Commons licence, unless indicated otherwise in a credit line to the material. If material is not included in the article's Creative Commons licence and your intended use is not permitted by statutory regulation or exceeds the permitted use, you will need to obtain permission directly from the copyright holder. To view a copy of this licence, visit http://creativecommons.org/licenses/by/4.0/ The Creative Commons Public Domain Dedication waiver (http://creativecommons.org/publicdomain/zero/1.0/) applies to the data made available in this article, unless otherwise stated in a credit line to the data. 
However, there are no validated randomized controlled trials (RCTs) on the choice of infusion route during maternal resuscitation, and most studies have not included cardiac arrest cases. Pregnant women have a particular circulatory situation in which the inferior vena cava is compressed by the enlarged uterus, so the usual choice of infusion route during resuscitation of adults may not be applicable.

Therefore, we decided to conduct a comprehensive review of the practicality of the infusion route in pregnant women with the purpose of scientifically supporting whether the infusion route should be secured above the diaphragm during pregnancy. We created a clinical question (CQ) from the algorithm and 2015 statements of the American Heart Association (AHA). This report is a scoping review of the question, "In cardiopulmonary resuscitation of pregnant women, should the infusion route be taken above the diaphragm for massive infusion?"

\section{Methods}

The maternal group within the JRC of the Guideline Editorial Committee established the CQ. However, since there are no valid studies on the location of the infusion route during resuscitation of pregnant women, we concluded that a systematic review would be difficult and decided to instead conduct a scoping review of all studies on the infusion route for pregnant women.

\section{Protocol and registration}

This study was systematized and conducted concerning the Preferred Reporting Items for Systematic reviews and Meta-Analyses (PRISMA) extension for Scoping Reviews checklist [4].

\section{Eligibility criteria}

Only articles published in peer-reviewed journals were included in the review, and articles consisting only of abstracts were excluded. Only literature published in English were included, while articles published in other languages were excluded. Literature on animals were excluded, and only studies on humans were included. The types of studies included were RCTs, non-RCTs (such as split time-series analyses, before-and-after comparative studies, cohort studies, case reports, and meta-analyses), case-concentration studies, reviews, and existing guidelines. Unpublished studies (e.g., conference abstracts and clinical trial protocols) were excluded.

\section{Information sources}

Articles published on or before December 07, 2019 were retrieved from MEDLINE/PubMed and Embase. The search strategy was constructed by Marie Furuta, PhD
Health Studies, an expert in public health (co-author of this paper).

\section{Search}

The search strategy is shown in Supplementary Material 1.

\section{Selection of sources of evidence}

Data charting of each literature was performed independently by two reviewers. In pairs sequentially evaluated the titles and abstracts, while screening of full-text articles were performed independently.

\section{Data charting process}

Population, concept, and context frameworks were created [5], as shown in Table 1. A data charting form was jointly developed by two reviewers to determine the relevant articles that should be extracted.

\section{Results}

Selection of sources of evidence

Figure 1 shows the PRISMA flowchart [6] for this scoping review.

\section{Characteristics of sources evidence}

The search for articles was performed on December 07, 2019 based on the search formula described in Supplementary Material 1. 1194 articles were extracted from MEDLINE/PubMed and 1959 articles were extracted from Embase. After title and abstract review, 265 articles met the eligibility criteria by deduplication and relevance screening. Supplementary Material 2 shows the list of references in which full-text screening was conducted. Full-text screening was then conducted, and 116 references were extracted for the final analysis.

\section{Results of individual sources of evidence}

Table 2 presents the details of the breakdown of the 116 articles.

The 116 articles included 78 studies on the infusion of fluids during cesarean section, 11 on the infusion of fluids during hemorrhage, 7 on the infusion of fluids during cardiac arrest, and 20 on the infusion of fluids for infection, thrombosis, and other conditions in pregnant

Table 1 PCC (Population, Concept, Context) frameworks

Population: A study on the infusion of fluids in pregnant women after 20 weeks of gestation.

Concept: RCT and non-RCT (split time-series analysis, before-and-after comparative studies, cohort studies, case reports, and meta-analysis) were included in studies of patients requiring intravenous infusion or intraosseous infusion due to cardiac arrest, massive bleeding, intraabdominal hemorrhage, cesarean section, severe infection, thrombosis.

Context: We searched the literature, regardless of the region in which the study was conducted, race, or differences in health care systems by medical area. 


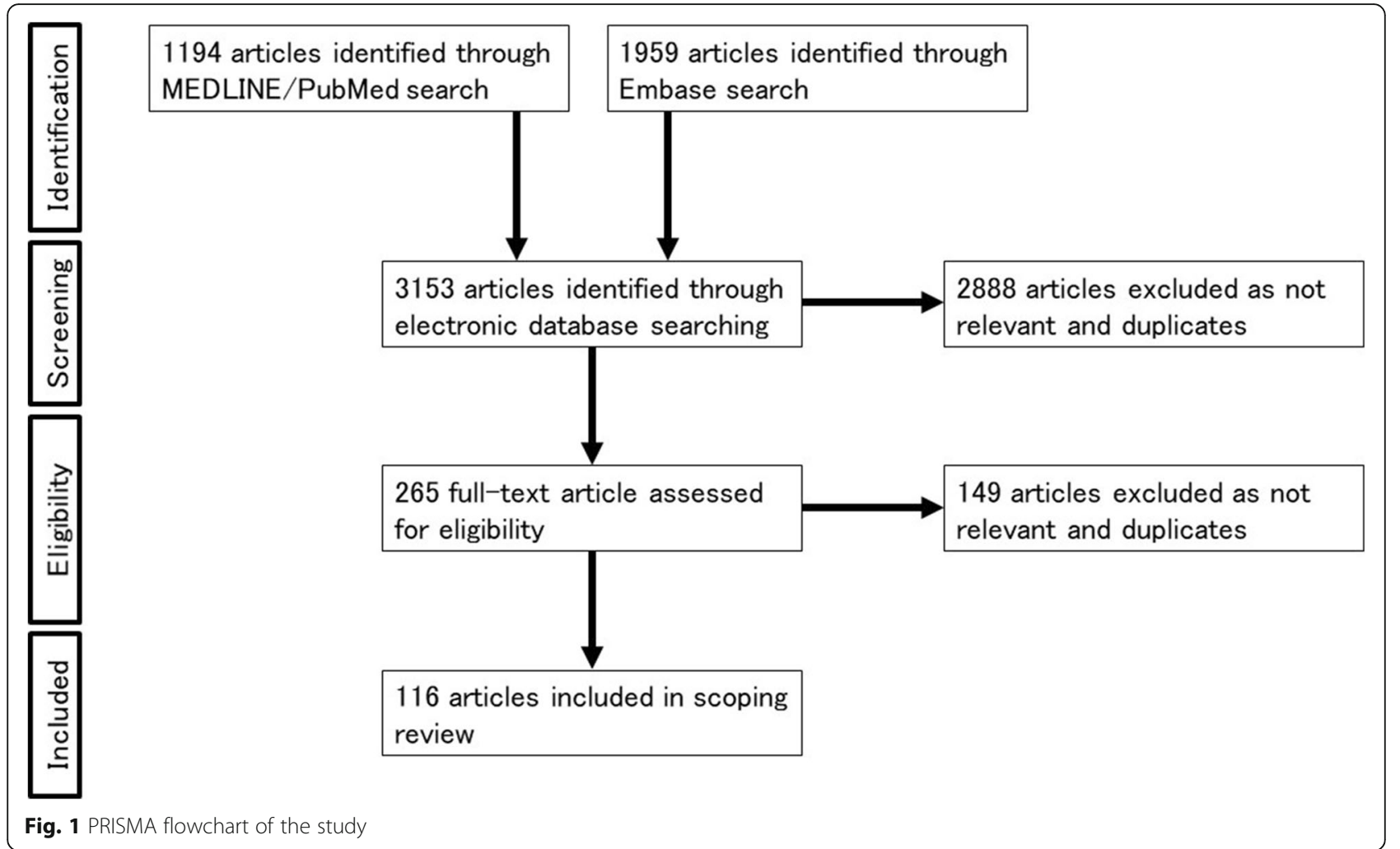

women based on the search formula described above. The location of the infusion route (upper or lower extremity) could be confirmed in only 17 studies, all of which used the upper extremity to secure the venous route. Table 3 shows a list of references that mention the infusion route.

We also conducted a comprehensive search for studies on maternal bone marrow tracts, but no relevant studies were identified.

\section{Summary of evidence}

To conduct a broad review of maternal infusion routes, a scoping review was performed. Some literature, including RCTs, were found related to the infusion of fluids during surgery and bleeding in pregnant women. However, there were no RCTs related to maternal infusion routes, hence, a systematic review was decided against.

Table 2 General characteristics of included articles

\begin{tabular}{|c|c|c|c|c|c|}
\hline & & \multicolumn{4}{|c|}{ Types of literature $(n=116)$} \\
\hline & & $\begin{array}{l}\text { Caesarean section } \\
(n=78)\end{array}$ & $\begin{array}{l}\text { Postpartum bleeding } \\
(n=11)\end{array}$ & $\begin{array}{l}\text { Maternal cardiac } \\
\text { arrest }(n=7)\end{array}$ & $\begin{array}{l}\text { Other complications in } \\
\text { pregnancyt }(n=20)\end{array}$ \\
\hline \multirow{9}{*}{$\begin{array}{l}\text { Study } \\
\text { design }\end{array}$} & $\mathrm{RCT}$ & 54 & 5 & 0 & 6 \\
\hline & $\begin{array}{l}\text { Prospective cohort } \\
\text { study }\end{array}$ & 15 & 0 & 0 & 2 \\
\hline & $\begin{array}{l}\text { Retrospective cohort } \\
\text { study }\end{array}$ & 0 & 1 & 1 & 1 \\
\hline & Case control study & 0 & 0 & 0 & 0 \\
\hline & Cross sectional study & 0 & 0 & 0 & 3 \\
\hline & Case control study & 0 & 0 & 0 & 0 \\
\hline & $\begin{array}{l}\text { Case report and case } \\
\text { series }\end{array}$ & 0 & 0 & 4 & 0 \\
\hline & Meta analysis & 3 & 0 & 0 & 0 \\
\hline & other & 6 & 5 & 2 & 8 \\
\hline
\end{tabular}


Table 3 All references that mention the location of the infusion route

\begin{tabular}{|c|c|c|c|c|}
\hline Author & Article type & $\begin{array}{l}\text { Published } \\
\text { year }\end{array}$ & Population & $\begin{array}{l}\text { Location of the intravenous } \\
\text { infusion route }\end{array}$ \\
\hline Pouta et al. [13] & $\begin{array}{l}\text { Randomized } \\
\text { controled trial }\end{array}$ & 1996 & Pregnant woman undergoing a cesarean section & Upper extremities \\
\hline King et al. [14] & $\begin{array}{l}\text { Randomized } \\
\text { controled trial }\end{array}$ & 1998 & Pregnant woman undergoing a cesarean section & Upper extremities \\
\hline Ngan et al. [15] & $\begin{array}{l}\text { Randomized } \\
\text { controled trial }\end{array}$ & 2000 & Pregnant woman undergoing a cesarean section & Upper extremities \\
\hline Desalu ei al [16]. & $\begin{array}{l}\text { Randomized } \\
\text { controled trial }\end{array}$ & 2005 & Pregnant woman undergoing a cesarean section & Upper extremities \\
\hline Ngan et al. [17] & $\begin{array}{l}\text { Randomized } \\
\text { controled trial }\end{array}$ & 2005 & Pregnant woman undergoing a cesarean section & Upper extremities \\
\hline Ngan et al. [18] & $\begin{array}{l}\text { Randomized } \\
\text { controled trial }\end{array}$ & 2008 & Pregnant woman undergoing a cesarean section & Upper extremities \\
\hline $\begin{array}{l}\text { Nuthalapaty } \\
\text { et al. [19] }\end{array}$ & Retrospective study & 2009 & $\begin{array}{l}\text { Study on infusion for pregnant and postpartum } \\
\text { patients }\end{array}$ & Upper extremities \\
\hline $\begin{array}{l}\text { Chatterjee et al. } \\
\text { [20] }\end{array}$ & Case report & 2011 & Massive obstetric haemorrhage & Upper extremities \\
\hline $\begin{array}{l}\text { El-Mekawy et al. } \\
\text { [21] }\end{array}$ & $\begin{array}{l}\text { Randomized } \\
\text { controled trial }\end{array}$ & 2012 & Pregnant woman undergoing a cesarean section & Upper extremities \\
\hline $\begin{array}{l}\text { Romdhani et al. } \\
\text { [22] }\end{array}$ & $\begin{array}{l}\text { Randomized } \\
\text { controled trial }\end{array}$ & 2014 & Pregnant woman undergoing a cesarean section & Upper extremities \\
\hline Cape et al. [23] & Retrospective study & 2014 & $\begin{array}{l}\text { Patients with peripherally inserted central catheter } \\
\text { during pregnancy }\end{array}$ & Upper extremities \\
\hline Zasa et al. [24] & $\begin{array}{l}\text { Randomized } \\
\text { controled trial }\end{array}$ & 2015 & Pregnant woman undergoing a cesarean section & Upper extremities \\
\hline $\begin{array}{l}\text { Onwochei et al. } \\
\text { [25] }\end{array}$ & Prospective study & 2017 & Pregnant woman undergoing a cesarean section & Upper extremities \\
\hline Ngan et al. [26] & $\begin{array}{l}\text { Randomized } \\
\text { controled trial }\end{array}$ & 2017 & Pregnant woman undergoing a cesarean section & Upper extremities \\
\hline Ngan et al. [27] & $\begin{array}{l}\text { Randomized } \\
\text { controled trial }\end{array}$ & 2017 & Pregnant woman undergoing a cesarean section & Upper extremities \\
\hline Ngan et al. [28] & $\begin{array}{l}\text { Randomized } \\
\text { controled trial }\end{array}$ & 2018 & Pregnant woman undergoing a cesarean section & Upper extremities \\
\hline $\begin{array}{l}\text { Webster et al. } \\
\text { [29] }\end{array}$ & Retrospective study & 2018 & massive obstetric hemorrhage & Upper extremities \\
\hline
\end{tabular}

\section{Conclusions}

In this study, we conducted a scpoing review to broadly review routes of maternal infusion. This comprehensive scoping review revealed that the number of studies mentioning the infusion route in detail is scarce, and the level of evidence for securing the infusion route above the diaphragm is small. However, there is no evidence of the adverse effects occurring when securing the infusion route above the diaphragm. The AHA recommendations further support an infusion route above the diaphragm, considering the pressure drainage of the inferior vena cava caused by an enlarged uterus in pregnant and nursing women, as detailed below.

The 2010 AHA Guideline, Part 12: Cardiac arrest in special situations, it was recommended that the infusion route be secured above the diaphragm [2].
The AHA likely came to this view considering the following special circulatory dynamics of pregnant and nursing women. Significant physiological changes occur in pregnant and nursing women, which differ from those in normal adults. In addition to increasing circulating blood volume up to $50 \%$, decreasing peripheral vascular resistance, and increasing in cardiac output, the enlarged uterus causes pressure drainage of the inferior vena cava and pelvic veins, resulting in partial venous hypertension and edema [7].

It is justifiable to secure an infusion route above the diaphragm so that infusions and administered drugs can reach the heart without passing through the distended inferior vena cava [8].

Although these recommendations are reasonable based on the special circulatory dynamics of pregnant and 
nursing women, they are not based on evidence from the literature. Some studies have suggested that an infusion route below the diaphragm should be avoided because an enlarged uterus pressurizes and inhibits venous return [9].

It is noteworthy that the scoping review revealed that there are no valid RCTs on the choice of infusion route in pregnant women. A high-quality RCT of infusion routes during maternal resuscitation seems impossible due to the ethical difficulties of randomization and blinding. However, conducting RCTs and systematic reviews comparing upper and lower extremity infusion routes in the future, including in non-pregnant women, can be useful to build further evidence.

In non-pregnant women, there were three observational studies of adult out-of-hospital cardiac arrest with a total of 34,868 patients comparing the upper and lower extremity infusion routes [10-12]. Compared to the use of the venous route in the upper extremities, the use of the bone marrow route in the lower extremities was associated with worse outcomes such as poor survival, with $<17$ patients discharged alive per 1000 cardiac arrest patients. These references compare the intravenous and intraosseous route with the target population being non-pregnant women. Although the above references need to consider inconsistency and indirection in this scoping review, it is possible that the outcome of cardiac arrest may be better if the infusion route is secured through the upper arm.

Pregnant women undergo significant physiological changes that differ from those of normal adults, due to pressure and drainage of the inferior vena cava and pelvic veins by the enlarged uterus. Therefore, despite a lack of evidence, it seems logical to secure the infusion route above the diaphragm when resuscitating a pregnant woman.

\section{Abbreviations}

AHA: American Heart Association; CoSTR: International Consensus Conference on Cardiopulmonary Resuscitation and Emergency

Cardiovascular Care Science With Treatment Recommendations; CQ: clinical question; PRISMA : Preferred Reporting Items for Systematic reviews and Meta-Analyses; RCTs : randomized controlled trials

\section{Supplementary Information}

The online version contains supplementary material available at https://doi. org/10.1186/s12873-021-00546-9.

Additional file 1. Supplementary Material 1: Detail of search strategy Additional file 2. Supplementary Material 2: full-text reference list assessed for eligibility

\section{Acknowledgments}

The authors would like to thank the members of the Japan Resuscitation Council, Maternal group.

Dr. Rie Kato, Dr. Jun Takeda, Dr. Masahiro Nakao, Dr. Tomoyuki Yamashita, Dr. Yoshihiro Yamahata, Dr. Masafumi Nii, Dr. Naosuke Enomoto, Dr. Yuki
Hosokawa, Dr. Shinji Baba, Dr. Naosuke Enomoto, Dr. Makoto Tsuji, Dr. Takahide Maenaka, members of the Japan Resuscitation Council, Dr. Hiroshi Nonogi, Dr. Mayumi Aibiki, Dr. Takanari Ikeyama, Dr. Tetsuya Isayama, Dr. Taku Iwami, Dr. Yasuhiro Kuroda, Dr. Tetsuya Sakamoto, Dr. Naoki Shimizu, Dr. Masao Nagayama, Dr. Chika Nishiyama, Dr. Tetsuo Hatanaka, Dr.

Shigeharu Hosono, and Dr. Tasuku Matsuyama.

\section{Authors' contributions}

Study design was concieved by EN, ST, SM, HT, and AS. Methodology was formulated by MF and AS. Formal analysis and investigation were performed by EN, ST, and MF. Review and editing were performed by EN and ST. All authors read and approved the final manuscript.

\section{Funding}

This research did not receive any specific grant from funding agencies in the public, commercial, or not-for-profit sectors.

Availability of data and materials

All data generated or analysed during this study are included in supplementary information files.

\section{Declarations}

Ethics approval and consent to participate

Not applicable.

\section{Consent for publication}

Not applicable.

\section{Competing interests}

The authors declare that they have no competing interest.

\section{Author details}

${ }^{1}$ Center for Maternal, Fetal and Neonatal Medicine, Saitama Medical Center, Saitama Medical University, 1981 Kamoda, Kawagoe-shi, Saitama 350-8550, Japan. ${ }^{2}$ Japan Resuscitation Council, Maternal group, Tokyo Japan, 2-5-4 Yoyogi, Sibuya-ku, Tokyo 151-0053, Japan. ${ }^{3}$ Department of Anesthesiology, Juntendo University Urayasu Hospital, 2-1-1 Tomioka, Urayasu-shi, Chiba 279-0021, Japan. ${ }^{4}$ Department of Obstetrics and Gynecology, Saitama Medical Center, Saitama Medical University, 1981 Kamoda, Kawagoe-shi, Saitama 350-8550, Japan. ${ }^{5}$ Department of Obstetrics and Gynecology, Mie University School of Medicine, 2-174 Edobashi, Tsu-shi, Mie 514-8507, Japan. ${ }^{6}$ Department of Human Health Sciences, Graduate School of Medicine, Kyoto University, 53 Kawahara-cho Shogo-in, Sakyo-ku, Kyoto 606-8507, Japan.

${ }^{7}$ Division of Emergency and Critical Care Medicine, Department of Acute Medicine, Nihon University School of Medicine, 30-1 Oyaguchi Kamimachi, Itabashi-ku, Tokyo 173-8610, Japan.

Received: 20 September 2021 Accepted: 24 November 2021

Published online: 03 December 2021

\section{References}

1. Hasegawa J, Sekizawa A, Tanaka H, Katsuragi S, Osato K, Murakoshi T, et al. Maternal Death Exploratory Committee in Japan., Japan Association of Obstetricians and Gynecologists. Current status of pregnancy-related maternal mortality in Japan: a report from the maternal death exploratory Committee in Japan. BMJ Open. 2016;6(3):e010304. https://doi.org/10.1136/ bmjopen-2015-010304.

2. Vanden Hoek TL, Morrison $\amalg$, Shuster M, Donnino M, Sinz E, Lavonas EJ, et al. Circulation 2010-part 12: cardiac arrest in special situations: 2010 American Heart Association guidelines for cardiopulmonary resuscitation and emergency cardiovascular care. Circulation. 2010;122(Suppl 3):S829-61. https://doi.org/10.1161/CIRCULATIONAHA.110.971069.

3. Jeejeebhoy FM, Zelop CM, Lipman S, Carvalho B, Joglar J, Mhyre JM, et al. Cardiac arrest in pregnancy: a scientific statement from the American Heart Association. Circulation. 2015;132(18):1747-73. https://doi.org/10.1161/CIR. 0000000000000300

4. Tricco AC, Lillie E, Zarin W, O'Brien KK, Colquhoun H, Levac D, et al. PRISMA extension for scoping reviews (PRISMA-SCR): checklist and explanation. Ann Intern Med. 2018;169(7):467-73. https://doi.org/10.7326/M18-0850. 
5. The Joanna Briggs institute: Joanna Briggs Institute Reviewers' Manual 2015. Australia: 2015

6. Moher D, Liberati A, Tetzlaff J, Altman DG. PRISMA group. Preferred Reporting Items for Systematic Reviews and Meta-Analyses: The PRISMA statement. PLOS Med. 2009;6(7):e1000097. https://doi.org/10.1371/journal. pmed.1000097.

7. Hill CC, Pickinpaugh J. Physiologic changes in pregnancy. Surg Clin North Am. 2008;88(2):391-401, vii. https://doi.org/10.1016/j.suc.2007.12.005

8. Hofmeyr GJ, Gülmezoglu AM, Novikova N. Prophylactic intravenous preloading for regional analgesia in labour. Cochrane Database Syst Rev. 2002:(2):CD000175.

9. Crochetière C. Obstetric emergencies. Anesthesiol Clin North Am. 2003; 21(1):111-25. https://doi.org/10.1016/S0889-8537(02)00026-3.

10. Feinstein BA, Stubbs BA, Rea T, Kudenchuk PJ. Intraosseous compared to intravenous drug resuscitation in out-of-hospital cardiac arrest. Resuscitation. 2017;117:91-6. https://doi.org/10.1016/j.resuscitation.2017.06 014.

11. Kawano T, Grunau B, Scheuermeyer FX, Gibo K, Fordyce CB, Lin S, et al. Intraosseous vascular access is associated with lower survival and neurologic recovery among patients with out-of-hospital cardiac arrest. Ann Emerg Med. 2018;71(5):588-96. https://doi.org/10.1016/j.annemergmed.201 7.11.015.

12. Mody P, Brown SP, Kudenchuk PJ, Chan PS, Khera R, Ayers C, et al Intraosseous versus intravenous access in patients with out-of-hospita cardiac arrest: insights from the resuscitation outcomes consortium continuous chest compression trial. Resuscitation. 2019;134:69-75. https:// doi.org/10.1016/j.resuscitation.2018.10.031

13. Pouta AM, Karinen J, Vuolteenaho OJ, Laatikainen TJ. Effect of intravenous fluid preload on vasoactive peptide secretion during caesarean section under spinal anaesthesia. Anaesthesia. 1996;51(2):128-32. https://doi.org/1 0.1111/j.1365-2044.1996.tb07698.x

14. King SW, Rosen MA. Prophylactic ephedrine and hypotension associated with spinal anesthesia for cesarean delivery. Int J Obstet Anesth. 1998;7(1): 18-22. https://doi.org/10.1016/S0959-289X(98)80023-X.

15. Ngan Kee WD, Khaw KS, Lee BB, Lau TK, Gin T. A dose-response study of prophylactic intravenous ephedrine for the prevention of hypotension during spinal anesthesia for cesarean delivery. Anesth Analg. 2000;90(6): 1390-5. https://doi.org/10.1097/00000539-200006000-00024.

16. Desalu I, Kushimo OT. Is ephedrine infusion more effective at preventing hypotension than traditional prehydration during spinal anaesthesia for caesarean section in African parturients? Int J Obstet Anesth. 2005;14(4): 294-9. https://doi.org/10.1016/j.ijoa.2005.05.002.

17. Ngan Kee WD, Khaw KS, Ng FF. Prevention of hypotension during spinal anesthesia for cesarean delivery: an effective technique using combination phenylephrine infusion and crystalloid Cohydration. Anesthesiology. 2005; 103(4):744-50. https://doi.org/10.1097/00000542-200510000-00012.

18. Ngan Kee WD, Lee A, Khaw KS, Ng FF, Karmakar MK, Gin T. A randomized double-blinded comparison of phenylephrine and ephedrine infusion combinations to maintain blood pressure during spinal anesthesia for cesarean delivery: the effects on fetal acid-base status and hemodynamic control. Anesth Analg. 2008;107(4):1295-302. https://doi.org/10.1213/ane. Ob013e31818065bc.

19. Nuthalapaty FS, Beck MM, Mabie WC. Complications of central venous catheters during pregnancy and postpartum: A case series. Am J Obstet Gynecol. 2009;201:311.e1-5.

20. Chatterjee DJ, Bukunola B, Samuels TL, Induruwage L, Uncles DR. Resuscitation in massive obstetric haemorrhage using an intraosseous needle. Anaesthesia. 2011;66(4):306-10. https://doi.org/10.1111/j.1365-2044.2 011.06629.x

21. El-Mekawy NM. Comparative study between ephedrine infusion vs. CO/post loading of fluids for prevention of hypotension in emergency cesarean section under spinal anesthesia. Egypt J Anaesth. 2012;28(3):193-8. https:// doi.org/10.1016/j.egja.2012.02.009

22. Romdhani C, Trabelsi W, Lebbi A, Naas I, Elaskri $H_{1}$ Gharsallah $H$, et al. Lower incidence of hypotension following spinal anesthesia with $6 \%$ hydroxyethyl starch preload compared to 9\%o saline solution in caesarean delivery. Tunis Med. 2014;92(6):406-10.

23. Cape AV, Mogensen KM, Robinson MK, Carusi DA. Peripherally inserted central catheter (PICC) complications during pregnancy. JPEN J Parenter Enter Nutr. 2014;38(5):595-601. https://doi.org/10.1177/0148607113489994.
24. Zasa M, Conci E, Marchignoli A, Pini R, Passeri L, Fanelli G, et al. Comparison of two different approaches to hypotension following spinal anaesthesia for caesarean delivery: effects on neonatal and maternal wellbeing. Acta Biomed. 2015:86(1):45-52.

25. Onwochei DN, Ngan Kee WD, Fung L, Downey K, Ye XY, Carvalho JCA. Norepinephrine intermittent intravenous boluses to prevent hypotension during spinal anesthesia for cesarean delivery: a sequential allocation dosefinding study. Anesth Analg. 2017;125(1):212-8. https://doi.org/10.1213/ANE. 0000000000001846

26. Ngan Kee WD, Tam YH, Khaw KS, Ng FF, Lee SWY. Closed-loop feedback computer-controlled phenylephrine for maintenance of blood pressure during spinal anesthesia for cesarean delivery: a randomized trial comparing automated boluses versus infusion. Anesth Analg. 2017;125(1):117-23. https://doi.org/10.1213/ANE.0000000000001974.

27. Ngan Kee WD. A random-allocation graded dose-response study of norepinephrine and phenylephrine for treating hypotension during spinal anesthesia for cesarean delivery. Anesthesiology. 2017;127(6):934-41. https:// doi.org/10.1097/ALN.0000000000001880

28. Ngan Kee WD, Lee SWY, Ng FF, Khaw KS. Prophylactic norepinephrine infusion for preventing hypotension during spinal anesthesia for cesarean delivery. Anesth Analg. 2018;126(6):1989-94. https://doi.org/10.1213/ANE. 0000000000002243.

29. Webster J, Larsen E, Booker C, Laws J, Marsh N. Prophylactic insertion of large bore peripheral intravenous catheters in maternity patients for postpartum haemorrhage: a cohort study. Aust N Z J Obstet Gynaecol. 2018:58(5):548-52. https://doi.org/10.1111/ajo.12759.

\section{Publisher's Note}

Springer Nature remains neutral with regard to jurisdictional claims in published maps and institutional affiliations.

Ready to submit your research? Choose BMC and benefit from:

- fast, convenient online submission

- thorough peer review by experienced researchers in your field

- rapid publication on acceptance

- support for research data, including large and complex data types

- gold Open Access which fosters wider collaboration and increased citations

- maximum visibility for your research: over $100 \mathrm{M}$ website views per year

At $\mathrm{BMC}$, research is always in progress.

Learn more biomedcentral.com/submissions 